\title{
FROM MECHANICAL BIOLOGICAL TREATMENT TO ANAEROBIC DIGESTION - CHALLENGES IN CHANGING PLANT OPERATIONS
}

\section{Axel Zentner *}

Technische Universitat Dresden Fachrichtung Wasserwesen Ringgold standard institution, Institute of Waste Management and Circular Economy, Pratzschwitzer Straße 1501796 Pirna, Dresden, Saxony 0179, Germany

Article Info:

Received:

30 November 2018

Revised:

17 February 2019

Accepted:

22 February 2019

Available online:

31 March 2019

Keywords:

MBT

$A D$

oFMSW

Bio waste

Process water

\section{ABSTRACT}

This paper presents the findings acquired in a study on the rearrangement of wet fermendation conditons in an anaerobic digestion (AD) process. As required by the federal law the rural districts "Elbe-Elster" and "Oberspreewald" (AEV) implemented a separate collection system for the organic fraction of municipal solid waste (oFMSW). Accordingly, the input material in $A D$ of the mechanical biological treatment plant in Freienhufen (operated by AEV) is going to be separately collected oFMSW instead of residual waste. The plant operator intends to reduce the investment costs. Thus, the experiment has to refer to the existing plant regime. In order to facilitate the rearrangement on the operating process, the following objectives were investigated: (1) boosting AD by reducing the particle size; (2) recirculating process water to maximum extent to reduce waste water treatment costs; (3) describing the properties of oFMSW in the course of the seasons. Different variations in pre-treatment, $A D$ and recirculation of process water were tested at lab-scale to the best possible course of action for the implementation in real life. The results show, that reducing the particle size has a minor impact; both on degradation efficiency and biogas production. A major impact on $A D$ can be observed for the varying composition of oFMSW in the course of the seasons. Additionally, the recirculation of process water affects the efficiency of the $A D$ by influencing the volumetric load. However, the recirculation ratio is limited by the ammonia concentration, since it might have an inhibiting effect on the microorganisms'.

\section{INTRODUCTION}

The mechanical biological treatment plant (MBT) in Freienhufen is used to stabilise residual waste. The landfill volumecan be reduced while using the organic content to produce biogas. Since the rural districts Elbe - Elster and Oberspreewald - Lausitz adapted their waste management to federal law regulations, the organic fraction from the municipal solid waste (oFMSW) will be collected separately in future.

Hence the anaerobic digestion (AD) process of the MBT has to be converted. The accomplishment has to refer to the existing operating regime to reduce investment costs. This contains a wet fermentation. In order to facilitate the conversion to a fitting operating process for oFMSW, suitable particle sizes and volumetric loads have to be examined. In addition, the liquid phase of the digestate is to be recirculated to the maximum extent to save both fresh water and waste water treatment costs. In the framework of the one year lasting experiment the approach was segmented/divided into five parts:

- Description of the quality and quantity of separately collected oFMSW in the course of the year;

- Pre-treatment of separately collected oFMSW in respect to an efficient operating regime and in regard to laboratory requirements;

- Elaboration of best practice in $A D$ according to the specifications made by the plant operator;

- Development of a process water recirculation system, while taking nutrient enrichment and contaminant accumulation into account;

- Assessment of AD's residuals (digestate) regarding the application as a fertilizer.

\section{CHARACTERISATION OF OFMSW IN TERMS OF QUALITY AND QUANTITY}

The oFMSW was collected separately in a two-week cycle for the two different areas. The sampling and pre-treatment at the plant were done by the operator according to the guideline "PN 98" of the "Joint Working Group of the Federal States for Waste" (LAGA). For that purpose, the heterogeneous oFMSW was in advance grinded to a 
particle size of approximately $20 \mathrm{~mm}$ and homogenized (Figure 1).

Subsequently, the sampling material was delivered to the Institute of Waste Management and Circular Economy (IAK). The material was once more sampled on-site following the technical rules of LAGA PN 98 (Figure 2). Approximately $6 \mathrm{~kg}$ of fresh matter (FM) were taken and pre-treated for $A D$. Another $6 \mathrm{~kg} \mathrm{FM}$ were set aside and stored for elution tests.

\subsection{Impact of the course of seasons and settlement structure}

The oFMSW samples were used for fresh as well as dry matter analytics. The analytical data of the substrates shows a typical overview of oFMSW's properties over the course of the seasons. The waste composition also differs along the settlement structure.

All samples with an even sampling number originate from rural areas with a bigger core of settlement. The samples with uneven numbers come from more rural areas. From April 2017 till March 201852 samples were taken over the duration of one year. An overview of the sampling numbers is given in Table 1.

Since the existing operating regime at MBT Freienhufen is adjusting the dry matter content to $6 \%$, the water content of oFMSW is of high priority. The water content is also an indicator for the waste composition and is related to the organic dry matter (Figure 3).

The content of harmful substances/contaminantes (e.g. metal, batteries, plastics) was below $0.5 \mathrm{wt} \%$. The oFMSW's water content is varying strongly in a range from $48-70 \%$. The lowest water content was measured in spring and the highest in winter.

The organoleptic investigation showed no deviation from past experiences with oFMSW. Colour and odour displayed typical characteristics. The visual check revealed that the colour composition of oFMSW in spring and autumn is dominated by green waste. Thus, rain events as well as the green waste/kitchen waste ratio had a measurable impact on the water content. The impact of the settlement structure is negligible since no tendencies were depicted.

Furthermore, the green waste content is related to the organic dry matter content. Green waste is scratched and raked from the ground surface. Due to this, soil is collected along with the green waste. This relation is displayed in Figure 4.

The oFMSW was dried and grinded to a particle size of $10 \mathrm{~mm}$. The distribution of particle sizes after sieving shows that the highest organic matter content can be
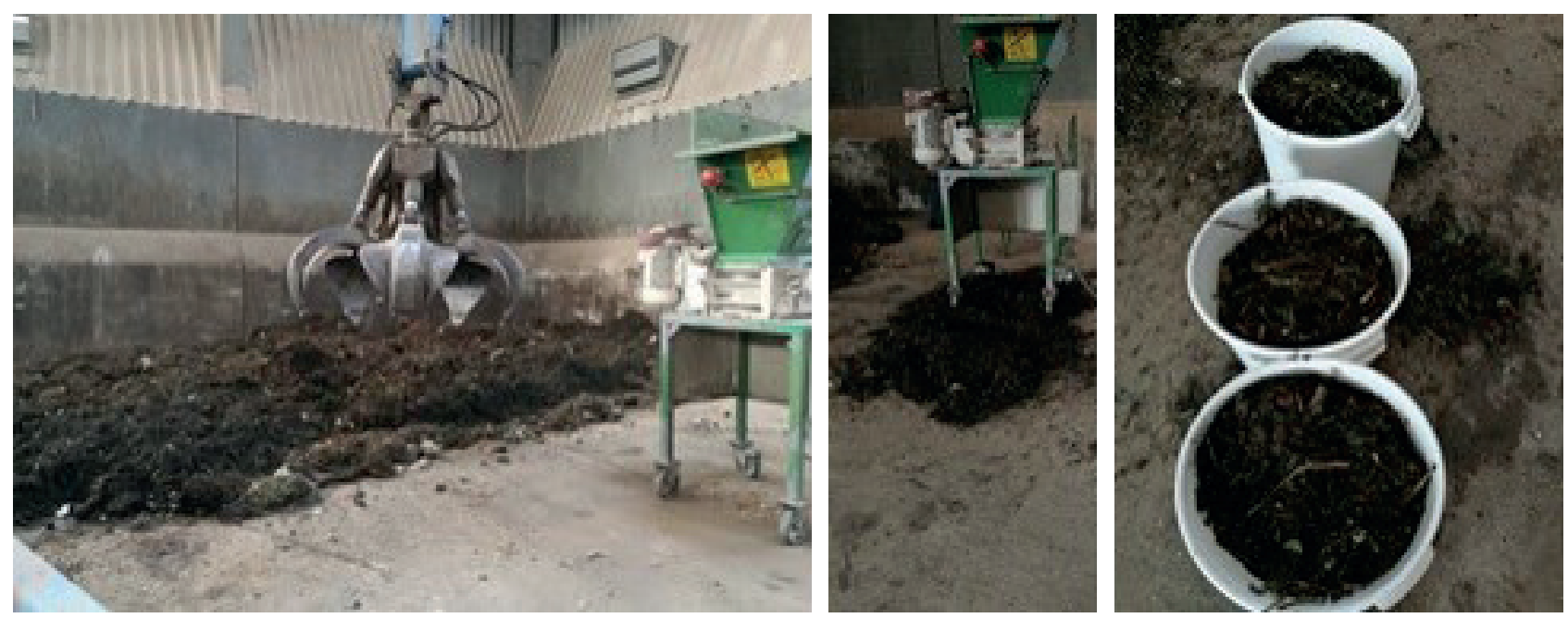

FIGURE 1: Sampling and pre-treatment of oFMSW on-site at MBT Freienhufen.
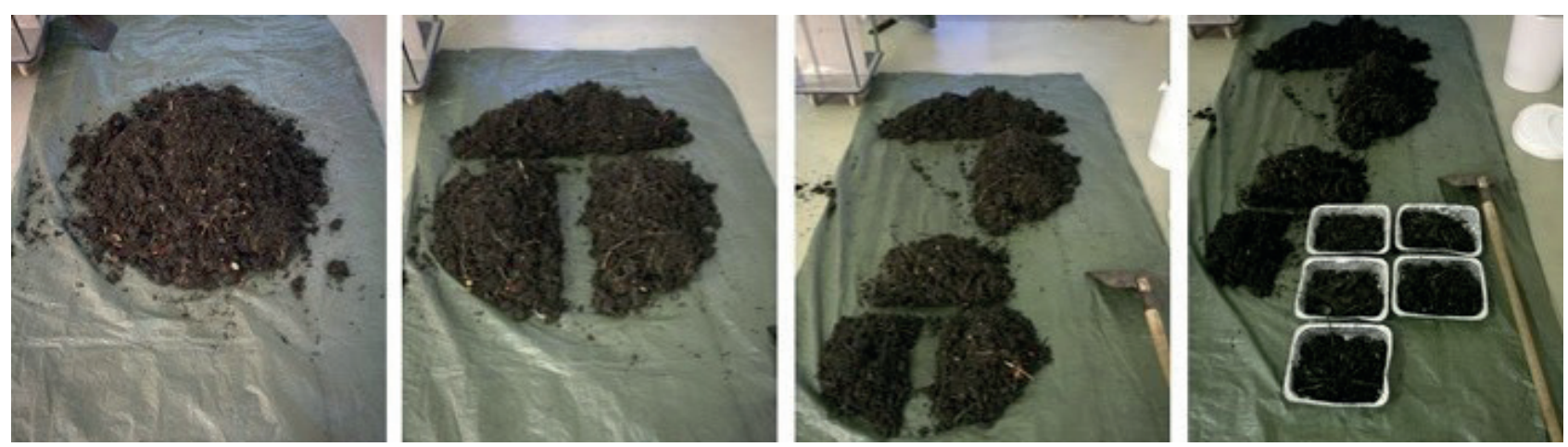

FIGURE 2: Sampling procedure for oFMSW at the IAK. 
TABLE 1: The assigned sample numbers for the respective months.

\begin{tabular}{c|cccccc}
\hline Month & Sampling Number & Month & Sampling Number & Month & Sampling Number \\
\hline $04 / 2017$ & BA 1 - BA 4 & $08 / 2017$ & BA 18 - BA 22 & $12 / 2017$ \\
\hline $05 / 2017$ & BA 5 - BA 9 & $09 / 2017$ & BA 36- BA 39 & BA 23 - BA 26 & BA 40 - BA 44 \\
\hline $06 / 2017$ & BA 10 - BA 13 & $10 / 2017$ & BA 27 - BA 30 & $02 / 2018$ \\
\hdashline $07 / 2017$ & BA 14 - BA 17 & $11 / 2017$ & BA 31 - BA 35 & $03 / 2018$ \\
\hline
\end{tabular}

found for the particle fraction between $2-4 \mathrm{~mm}$. The relative concentration of organic matter content increases from $27 \%$ for a particle sizes of less than $0.63 \mathrm{~mm}$ and to $60 \%$ for a particle size of $4 \mathrm{~mm}$. Thus, the above mentioned thesis was proven to be correct. When scratching and raking green waste from the surface of the ground, inert materials such as sand, stones and soil are collected as well.

\subsection{Chemical properties of oFMSW}

In addition, the bio-waste was analysed in the laboratory in regards to relevant parameters for $A D$. The focus was on nutrients (e.g. ammonia, TKN, sulphur, phosphorous, TOC) and heavy metals (e.g. Pb, Cd, Zn) (Table 2).

According to the analytical data inhibiting effects are not to be expected. The obtained data are in accordance with literature values as well as personal experiences (Zentner, 2015), (Adwiraah, 2015).

Most of the carbon present, approximately $98 \%$, isderives from organic carbon. The carbon content increased in November 2017 (BA 32). From this point on till the end of the experiment it was $30-55 \%$ higher than in the spring and summer of 2017. This is caused by the gradual acceptance of the new sorting system by the household, which lead to a higher share of kitchen waste in the oFMSW.
The optimal C:N:P:S-ratio of > 600:15:5:1 cannot be adjusted by exclusively using oFMSW for AD (Aschmann et al., 2007). It can be assumed that this will lead to a decrease in biogas production, due to a reduced carbon source and the ammonification caused through the nitrogen surplus.

\section{METHODOLOGY}

The investigations were performed under laboratory conditions. The reactors were operated with a specific volume of three litres. The inoculum, cow manure, was fed quasi-contionusly into the AD. For this purpose, feeding and sampling took place five times a week from Monday to Friday. Five incremental samples of one week were mixed to one sample and conditioned for analytics. The focus of the process variation was on:

- Particle size of oFMSW for the feed-in process;

- Ratio of recirculated process water and fresh water in the feed-in process;

- Accumulation of process-inhibiting substances.

Therefore, comprehensive analyses were conducted weekly to characterize both the solid and the liquid phase of the digestate. These include important parameters for AD and composting as for instance TOC, DOC, TKN, ammo-

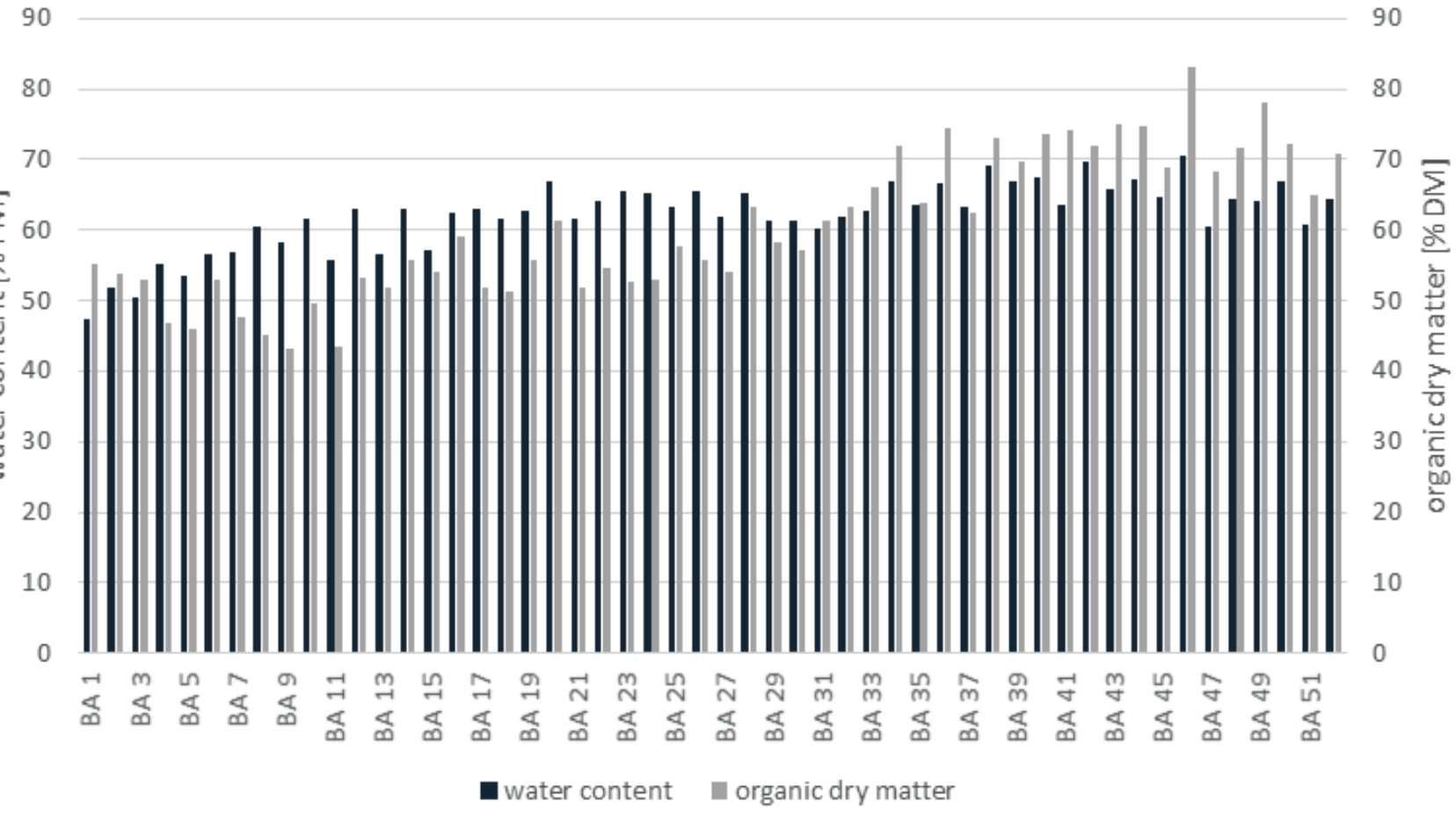

FIGURE 3: Sampling of oFMSW at IAK. 


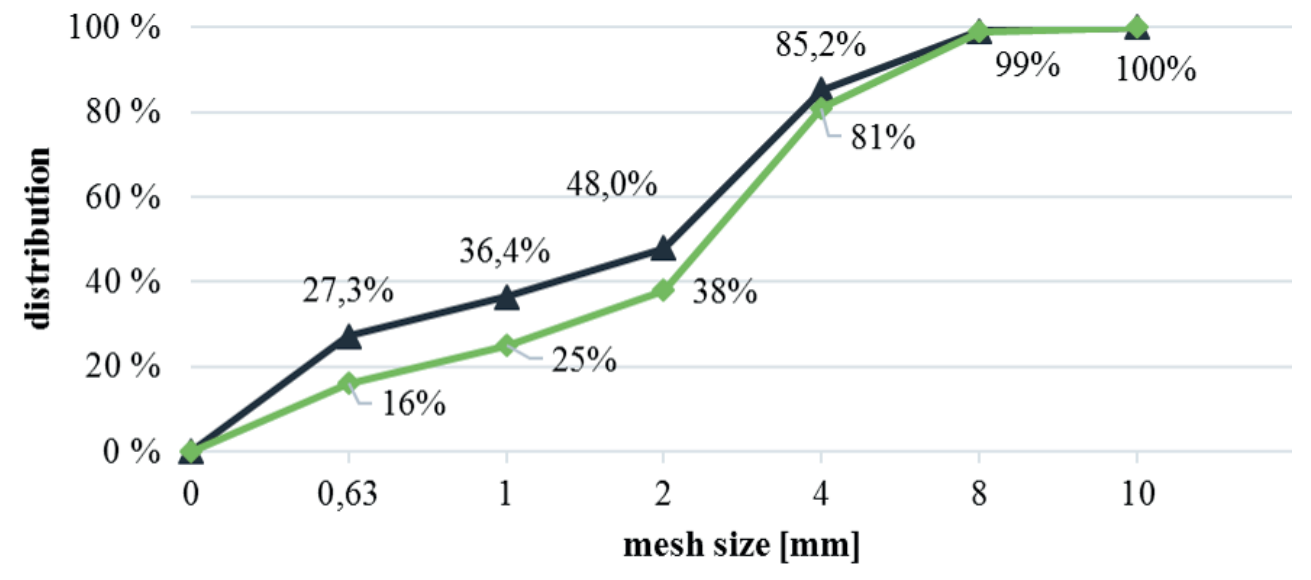

$\leftarrow$ particle distribution $\leadsto$ distribution of organic matter

FIGURE 4: Linear regression of the partical distribution acquired through sieving and the respective organic matter content.

nium, COD, phosphate, organic acids, FOS/TAC, nutrients and heavy metals. Additionally, the biogas composition was measured daily to evaluate the effect of varying volumetric loads and to determine critical moments caused by recirculation of the process water. Finally, the liquid and solid phase of the digestate will be evaluated in regards to their applicability as fertilizer.

\subsection{Pre-treatment of oFMSW for experimental inve- stigations}

As shown in Chapter 2 the sampling of the separately collected oFMSW took place at the plant site as well as the IAK. The particle size was $20 \mathrm{~mm}$. Larger wooden components were sorted out since they are not biodegradable in the AD. These wooden components served as structure material in subsequently conducted composting processes. By drying the bio-waste at a temperature of $105^{\circ} \mathrm{C}$ for 24 hours different effects were achieved. On the one hand the bio-waste was stabilized, so a steady quality can be guaranteed. On the other hand, the substrate was grinded to various particle sizes (Figure 5). The particle sizes ranged from $10 \mathrm{~mm}$ to $2 \mathrm{~mm}$, in order to determine the dependency between the surface area and degree of degradation.

TABLE 2: Chemical properties of oFMSW.

\begin{tabular}{c|ccc} 
Parameter & Unit & Arithmetic average \\
\hline Ammonia & {$[\mathrm{mg} / \mathrm{g}]$} & $1.75 \pm 0.56$ \\
\hline TKN & {$[\mathrm{mg} / \mathrm{g}]$} & $14.51 \pm 2.29$ \\
Sulphur & {$[\mathrm{mg} / \mathrm{g}]$} & $2.39 \pm 0.49$ \\
\hline Phosphorous & {$[\mathrm{mg} / \mathrm{g}]$} & $2.74 \pm 0.54$ \\
\hdashline TC & {$[\mathrm{mg} / \mathrm{g}]$} & $317.81 \pm 49.59$ \\
TOC & {$[\mathrm{mg} / \mathrm{g}]$} & $311.62 \pm 56.14$ \\
$\mathrm{~Pb}$ & {$[\mathrm{mg} / \mathrm{g}]$} & $0.017 \pm 0.11$ \\
$\mathrm{Cd}$ & {$[\mathrm{mg} / \mathrm{g}]$} & $<\mathrm{LOD}$ \\
\hline $\mathrm{Zn}$ & {$[\mathrm{mg} / \mathrm{g}]$} & $0.128 \pm 0.35$ \\
\hline
\end{tabular}

\subsection{AD in experimental scale}

The experimental investigation was realised in two stages. The first stage was a preliminary test series consisting of three reactors with a specific volume of three litres. Two reactors were fed with dried and grinded bio-waste and used cow manure as an inoculum. The third reactor only contained cow manure as a blank value measurement. The pretests' aim was:

- The adaptation of the microorganisms;

- Adjusting stable process conditions;

- $\quad$ Setting the dry matter content to $10.5 \%$;

- Finding a suitable way to dewater the digestate to obtain process water.

The second stage depicts the set up of the main experiment, which consisted of six reactors (Figure 6). Two reactors were driven exclusively with cow manure. The other four reactors represented two diffrent scenarios with two set ups each as a control. The difference lay in the grain size distribution and an improved fresh water substitution through process water recirculation.

The process was based on the currently operating $A D$ in MBT Freienhufen. Thus, the retention time was adjusted to 25 days under mesophilic conditions at $35^{\circ} \mathrm{C}$. The dry matter content was raised from 6 to $10.5 \%$, since stiring grinded oFMSW is easier than residual waste, as their is a lower resistancy. The feeding of the reactors took place quasi-continuously from Monday till Friday. Hence, the dried and grinded oFMSW was mixed with fresh water in allignment with the retention time in the reactor. Following adjustments were made:

- Different particle sizes were fed: 10/8/4/2 mm;

- Fresh water was gradually substituted by recirculated process water: $\approx 50 / 65 / 75 / 100 \%$.

In the starting set up the largest particle size of $10 \mathrm{~mm}$ in the " $A$ "-reactors and $8 \mathrm{~mm}$ in the " $B$ "-reactors was used. Subsequently, the particle size in "B"-reactors was scaleddown to $4 \mathrm{~mm}$ to determine the dependency between the surface area and the degree of degradation. Furthermore, 

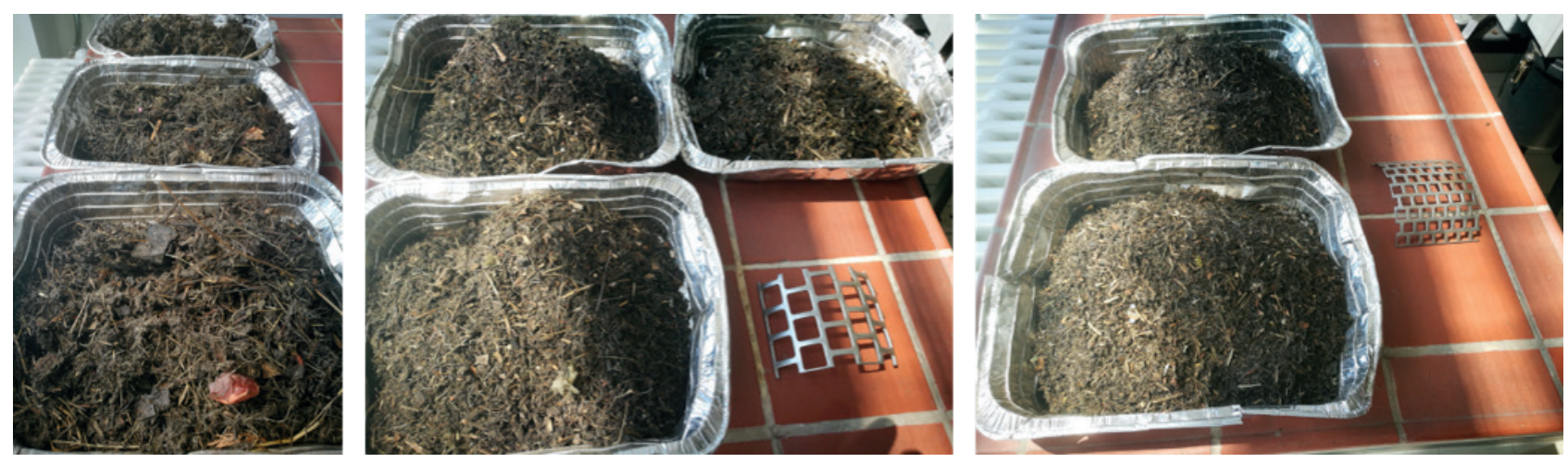

FIGURE 5: Dried and grinded organic waste in different particle sizes.

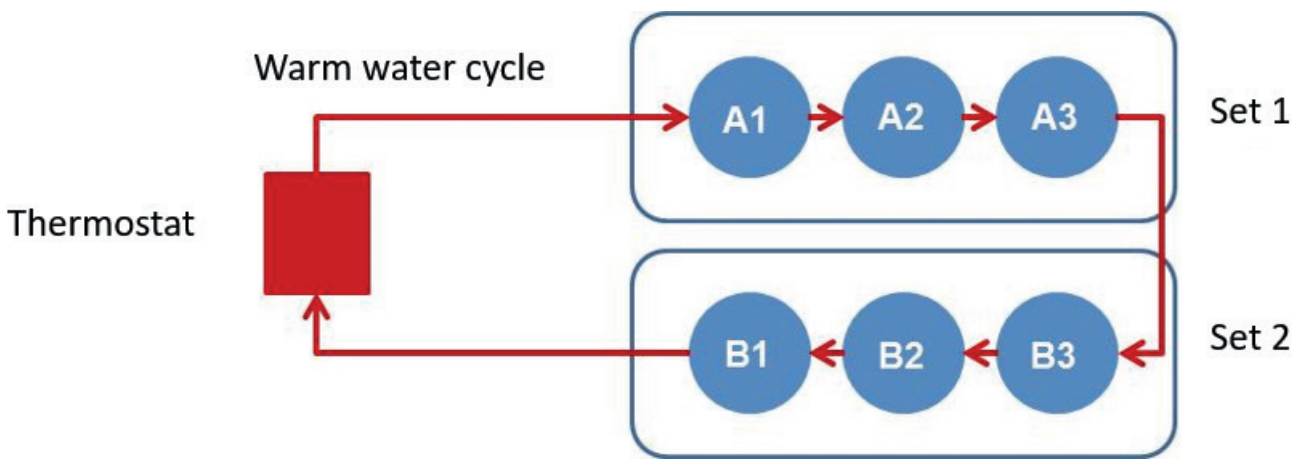

FIGURE 6: Setting of AD reactors in lab-scale at IAK.

the recirculation of process water was added to evaluate the impact of process water on an anaerobic environment. The ratio of the fresh water substitution was chosen to be $50 \%$ at the beginning, since the process water had a small organic load and contained minimum load of harmful substances. In the further course, the substitution rate was increased to $65 \%$, while not changing the particle size. This was done to evaluate the effect of an increased amount of recirculated process water on the process.

The performance of the " $B$ "-reactors was inferior to the one of the " $\mathrm{A}$ "-reactors. For that reason, the process variation was altered considerably after 12 weeks to determine both, the influence of the feedstock and the quality of equipment. Thus, in the comparative scenario, the " $B$ "-reactors and " $A$ "-reactors were fed with particles of a respective size of $10 \mathrm{~mm}$ and $2 \mathrm{~mm}$. This set-up was left for 14 weeks. Within this period, the substitution of fresh water with process water was increased gradually to $100 \%$ to assess the maximum effect of recirculation on the process.

The results obtained from varying the process (parameters), led to the assumption that ammonia will accumulate in the liquid phase. Thus, to prevent inhibiting effects the substition of fresh water with process water was gradually reduced to $65 \%$. Additionally, a larger particle size of $4 \mathrm{~mm}$ was selected for the oFMSW, since smaller particles were hindering the extration of digestate by clogging the outlet valve. After harmonising the " $\mathrm{A}$ "- and " $\mathrm{B}$ "-reactors the feeding procedure was changed. Simultaneous experiments indicated an influence of the feeding intervall on the biogas production. Therefore, the feeding interval was adjusted to take place three days a week (discontinuos) instead of five days a week (quasi-contiuous).

All of the variations should last at least 25 day to ensure the compliance with the hydraulic retention time.

\subsection{Process water recirculation}

The sampling took place simultaneously to the feeding. Five incremental samples taken in one week were unified to one mixed sample and prepared for the analysis. In accordance with the retention time period, $168 \mathrm{~g}$ were removed from the $A D$ reactor per day; which sums up to $840 \mathrm{~g}$ per week. Subsequently the gathered digestate was separated into a solid and a liquid phase (Figure 7).

\subsection{Biogas measurement}

The reactors' biogas was collected in gas bags. The biogas measurement was conducted simultaneaously with the feed-in process five times a week. Based on this, the daily biogas production could be measured and the weekly biogas amount determined. The biogas bags were connected to a gas measurement equipment (Visit-03 by Messtechnik Eheim) to analyze the composition of the biogas. Thus the concentration of methan, carbon dioxide, hydrogen and sulphur hydrogen could be determined. Subsequently, the analyzed biogas went through a volume flow rate measurement. The gained results were normalized by back-calculating the temperature and barometric pressure. 

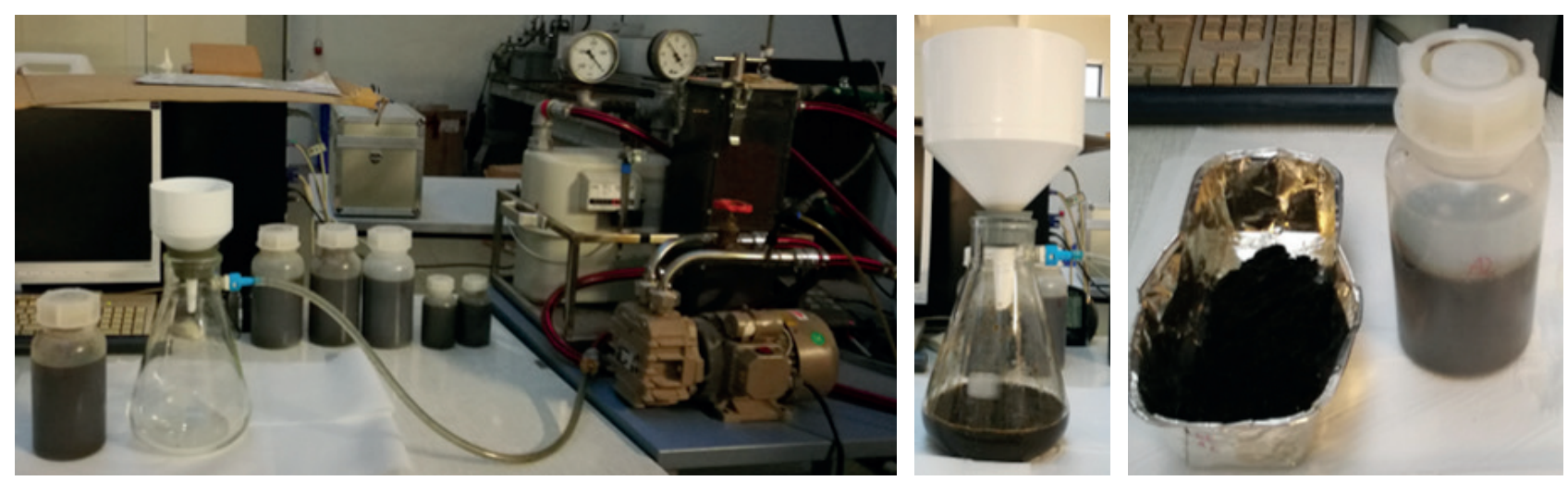

FIGURE 7: Dewatering of digestate.

\section{RESULTS OF MAIN AD EXPERIMENTS}

Varying scenarios were performed during the long-term experiment. Table 3 provides an overview of the adjusted parameters for each set-up.

\section{1 $\mathrm{pH}$, conductivity and redox potential}

The sampling was conducted five times a week from Monday till Friday. Immediately and on-site the conductivity, $\mathrm{pH}$ value and redox potential were measured to evaluate the process stability (Table 4 ).

The $\mathrm{pH}$ value decreased, from 7.8 to a stable range between 7.2 to 7.35 independently from the process variation. The high starting initial value is caused by cow manure, which is used as an inoculum. Since one stage reactors performed the $\mathrm{AD}$ the $\mathrm{pH}$ was kept at a stable state. This provides ideal circumstances for the preformance of acetogenic and methanogenic microorganisms (Aschmann et al., 2007), (Schulz, 1996).

The conductivity decreased from $17.8 \mathrm{mS} / \mathrm{cm}$ to a stable range between 10 to $12 \mathrm{mS} / \mathrm{cm}$ independently from process variation. The high inital value is also connected to the cow manure. In this case, the conductivity did probably not increased, because the concentration of free ions was higher. Since the conductivity was below $30 \mathrm{mS} / \mathrm{cm}$, inhibiting effects on methanogenic miccroorganisms are not likely to occur (Roitsch and Büscher, 2009).

The redox potential remained stable at -400 to $-300 \mathrm{mV}$ within the first six months of the main experiment; independently from process variation. Thus, ideal conditions were present for acetogenic and methanogenic microorganisms. At the end of the experiment the redox potential raised to $200 \mathrm{mV}$. After comparing the results with simultaneously conducted experiments, it can be concluded that the measuring device must have been non-conforming.

\subsection{Production and composition of biogas}

The specific biogas yields were approximately $180 \mathrm{NL} /$ (kg org. DM). The yields increased over time (Figure 8) until approx. $240 \mathrm{NL} /(\mathrm{kg}$ org. DM). The yields were higher in the A-reactors than in the B-reactors; even when the process parameters was changed in regards of the particle size and ratio of recirculated process water. In December a clear change took place and the yields achieved peaks of approximately $500 \mathrm{NL} /(\mathrm{kg}$ org. DM). The results were evidently comparable to literature values (Zentner, 2015). This leads to the assumption that biogas production is not influenced by varying the particle size and ratio of recirculated process water. Moreover, feeding and volumetric loading will have an impact on the biogas production. According to Figure 9 the biogas production is related to volumetric loading. The volumetric load increased over time since

TABLE 3: Description of the scenario variation.

\begin{tabular}{|c|c|c|c|c|}
\hline Timeframe/substrate & Reactor A2/A3 & Reactor B2/B3 & Process water & Feeding \\
\hline BA 14-15 & $10 \mathrm{~mm}$ & $8 \mathrm{~mm}$ & $0 \%$ & Quasi-continuous \\
\hline BA16-19 & $10 \mathrm{~mm}$ & $8 \mathrm{~mm}$ & $50 \%$ & Quasi-continuous \\
\hline BA 20-24 & $10 \mathrm{~mm}$ & $4 \mathrm{~mm}$ & $50 \%$ & Quasi-continuous \\
\hline BA 25 & $10 \mathrm{~mm}$ & $4 \mathrm{~mm}$ & $65 \%$ & Quasi-continuous \\
\hline BA 26-30 & $2 \mathrm{~mm}$ & $10 \mathrm{~mm}$ & $65 \%$ & Quasi-continuous \\
\hline BA 31-37 & $2 \mathrm{~mm}$ & $10 \mathrm{~mm}$ & $75 \%$ & Quasi-continuous \\
\hline BA 38-39 & $2 \mathrm{~mm}$ & $10 \mathrm{~mm}$ & $100 \%$ & Quasi-continuous \\
\hline BA 40-41 & $2 \mathrm{~mm}$ & $2 \mathrm{~mm}$ & $100 \%$ & Quasi-continuous \\
\hline BA $42-44$ & $2 \mathrm{~mm}$ & $2 \mathrm{~mm}$ & $75 \%$ & Quasi-continuous \\
\hline BA $45-46$ & $4 \mathrm{~mm}$ & $4 \mathrm{~mm}$ & $75 \%$ & Discontinuous \\
\hline BA 47-52 & $4 \mathrm{~mm}$ & $4 \mathrm{~mm}$ & $65 \%$ & Discontinuous \\
\hline
\end{tabular}


TABLE 4: Process stability in terms of $\mathrm{pH}$, conductivity and redox potential.

\begin{tabular}{|c|c|c|}
\hline Parameter & Reactor A2/A3 & Reactor B2/B3 \\
\hline $\mathrm{pH}$ & \multicolumn{2}{|c|}{ Stabilization at $\mathrm{pH}$ of 7.2 to 7.35} \\
\hline conductivity & \multicolumn{2}{|c|}{ Stabilization at 10 to $12 \mathrm{mS} / \mathrm{cm}$} \\
\hline redox potential & Varying redox pote & en -400 to $-200 \mathrm{mV}$ \\
\hline
\end{tabular}

the organic content of oFMSW accumulated continuously in the recirculated process water. Hence, the volumetric load increased from approximately 2.2 to $3.6 \mathrm{~kg}$ org. DM/ $\left(m^{3 *} d\right)$. Another effect occurred in relation to the feeding procedure. At Christmas break the feeding was converted from quasi-continuous to discontinuous. In other words, feeding was reduced from five times a week to 3 times a week. Simultaneously the specific biogas yield increased dramatically. After Christmas break the feeding was reconverted to quasi-continuous feeding and the biogas yield decreased again.

The composition of biogas was measured five times a week along with the sampling. As seen in the figures above the development of the biogas composition followed the same trends. Methane concentration increased over time from 45 to $52 \%$ and according to the increase in volumetric loading (Figure 10). Thus, the maximum volumetric load is not reached. Under other circumstances the biogas yield and the methane concentration would have decreased (Wellinger et al., 1991).

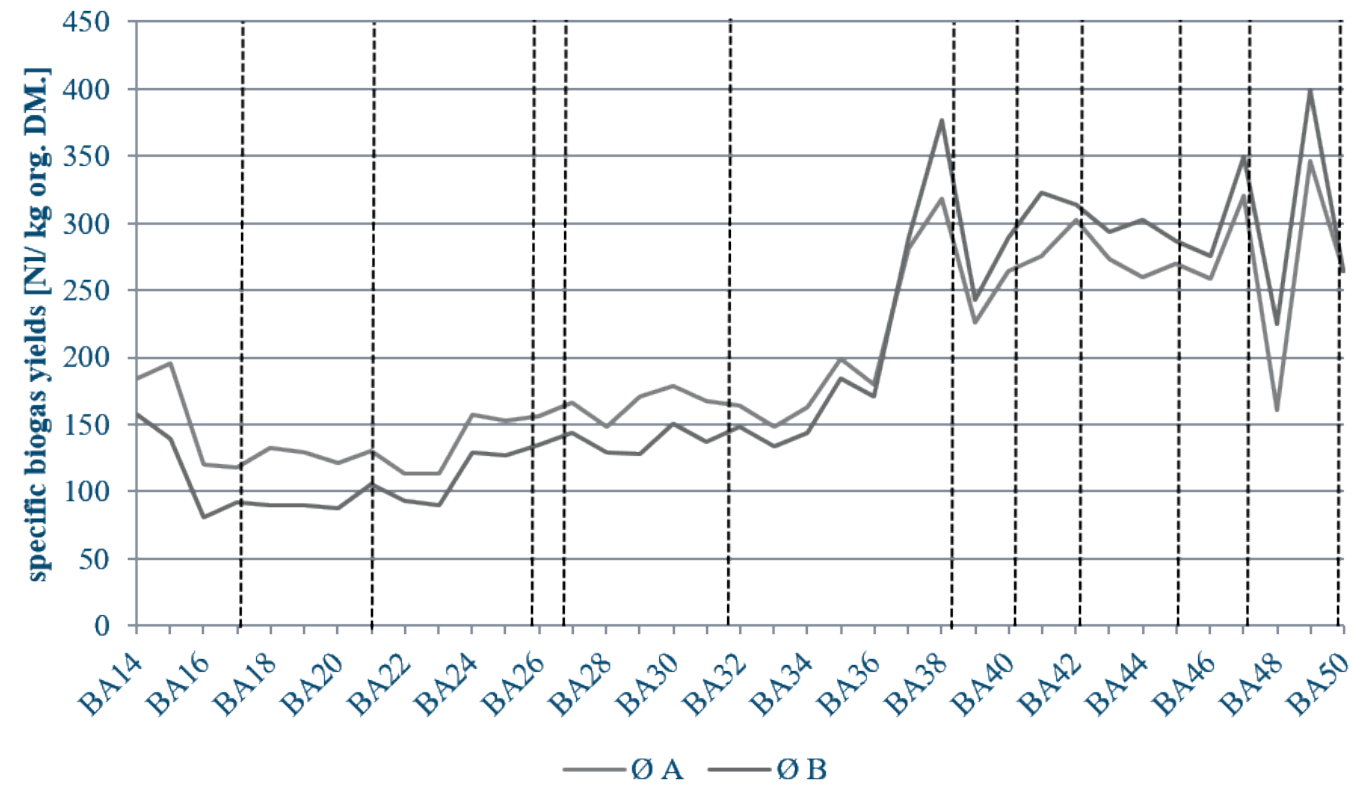

FIGURE 8: Excerpt of specific biogas yield.

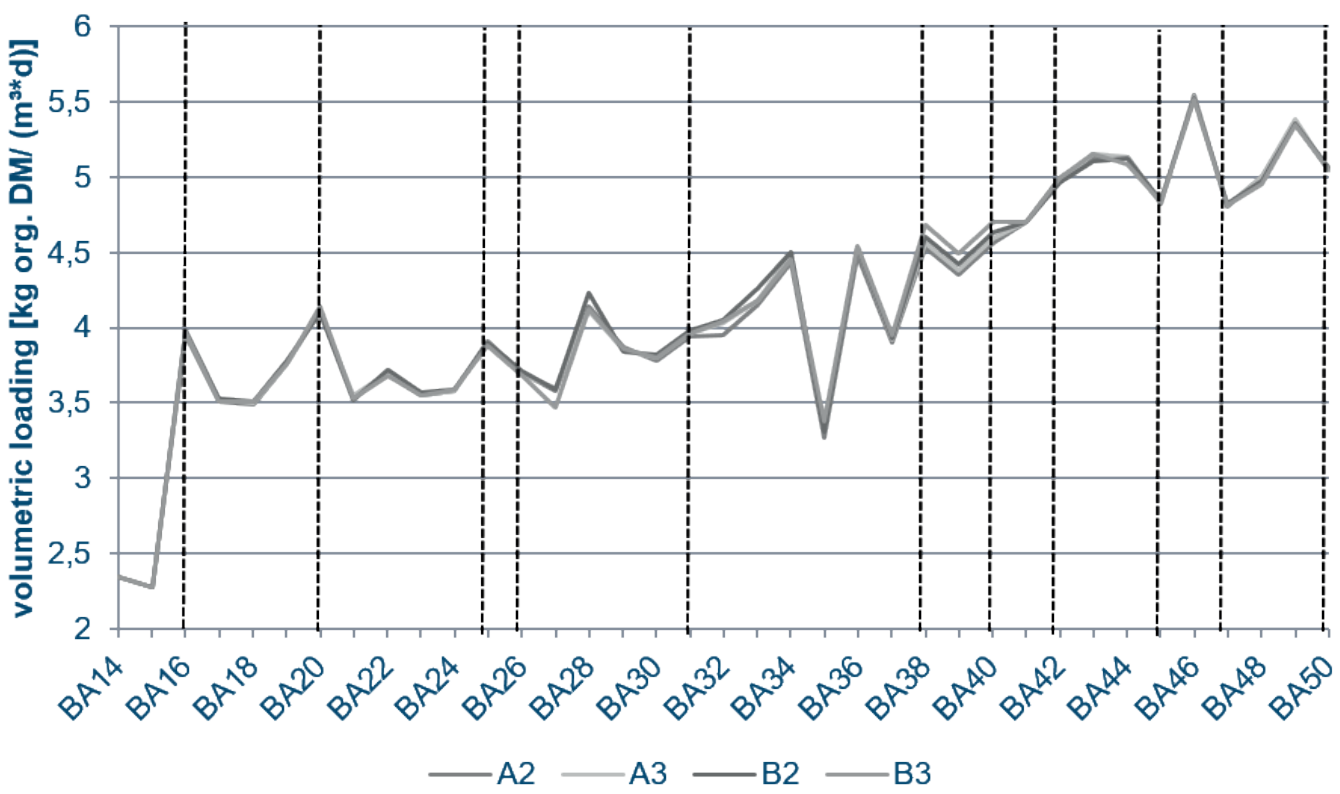

FIGURE 9: Excerpt of volumetric loading. 
The measured concentrations for hydrogen and hydrogen sulphide are negligible, as they were below 200 ppm, and thus within the related measurement tolerance (Figure 11). There is no tendency, which would be in need of extrapolation. At the end of the experiment the concentration of hydrogen sulphide increased. This effect is related to process water recirculation and should be investigated in future. Gaps in Figure 10 and 11 can be explained with technical malfunctions.

\subsection{Solid and liquid phase of digestate}

The digestate was evaluated for the separate utilization of solid and liquid phases. Therefore, both phases were analysed for inhibiting effects occurring in $A D$ and composting. The investigated parameters are presented in Table 5.

\subsubsection{Liquid Phase}

The liquid phase gained by dewatering the digestate was intended to be the reciruclated process water. By this, fresh water could be substituted and waste water avoided. For this reason, the quality and quantity of the liquid phase were evaluated. Following brief description gives an idea of the procedure.

The dry matter content of the liquid phase increased from approximately 3 to $7.7 \%$ within the main AD experiment. As could be seen from the particle size distribution in Chapter 2.1, oFMSW contains a large amount of

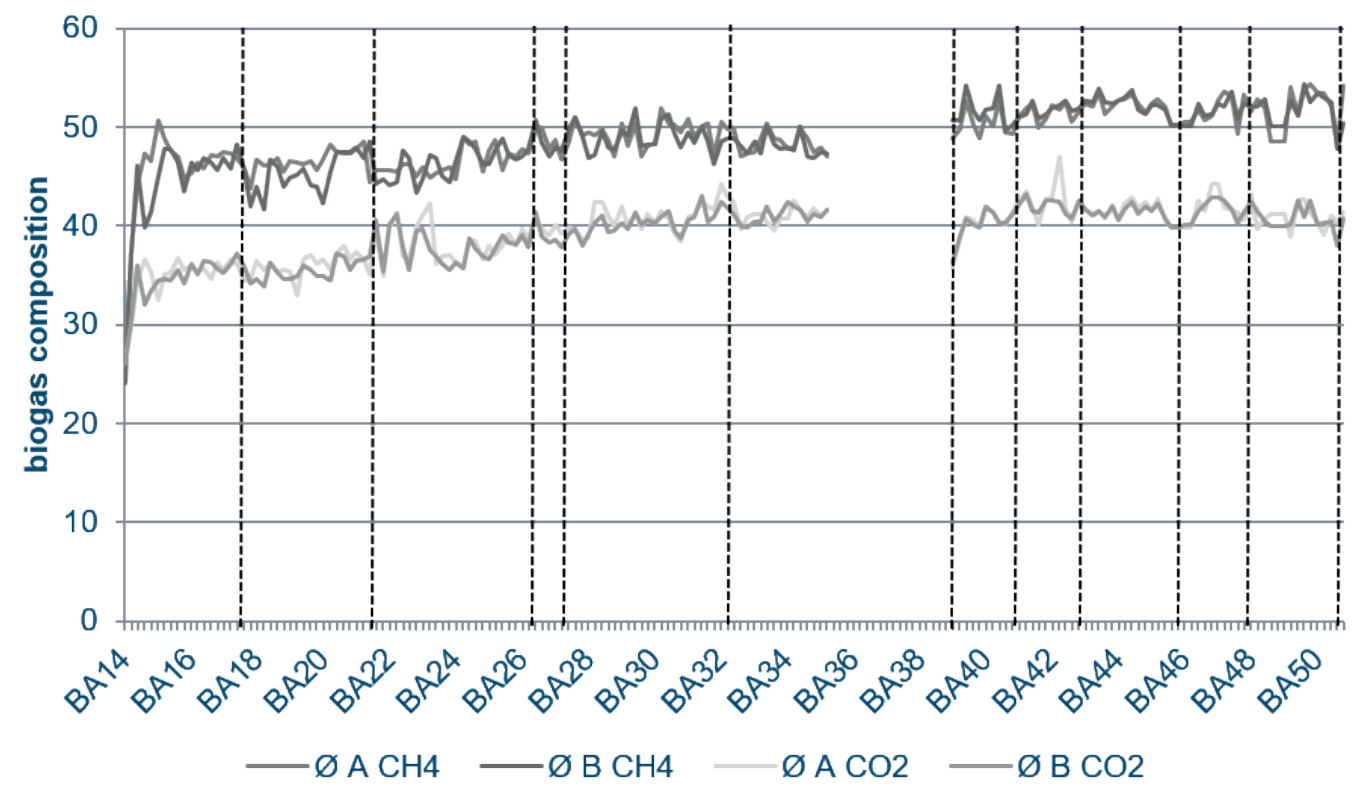

FIGURE 10: Methane and carbon dioxide production.

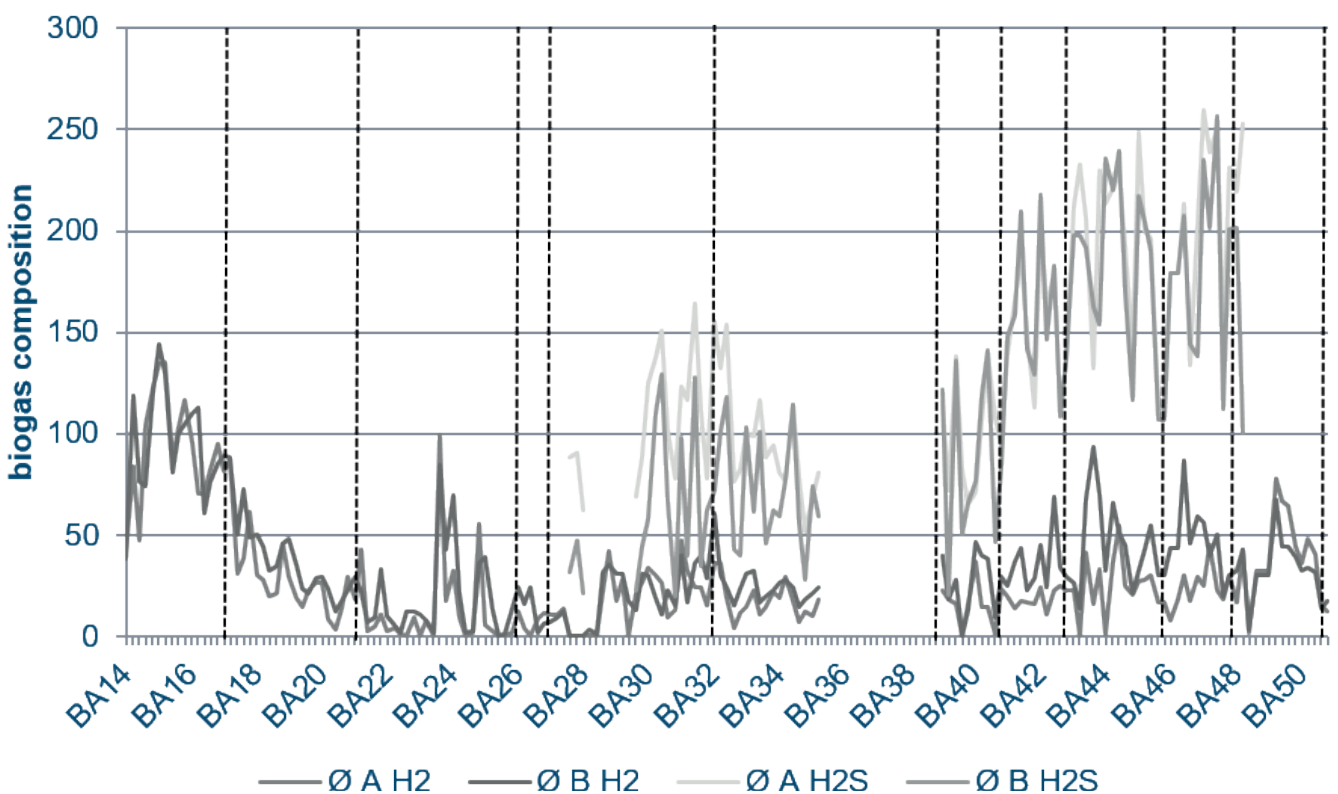

FIGURE 11: Occurance of hydrogen and hydrogen sulphide. 
TABLE 5: Investigated parameters in solid and liquid phase of digestate.

\begin{tabular}{l|c|c}
\hline Parameter & Solid phase & Liquid phase \\
\hline Water content & $\mathrm{X}$ & $\mathrm{X}$ \\
\hline Org. DM & $\mathrm{X}$ & $\mathrm{X}$ \\
\hline Total Kjeldahl Nitrogen & $\mathrm{X}$ & $\mathrm{X}$ \\
\hline Ammonia & & $\mathrm{X}$ \\
\hline Total Carbon & $\mathrm{X}$ & \\
\hline Total Organic Carbon & $\mathrm{X}$ & \\
\hline Total Phosphorous & $\mathrm{X}$ & \\
\hline Total Sulphur & $\mathrm{X}$ & \\
\hline Dissolved Organic Carbon & & $\mathrm{X}$ \\
\hline Chemical Oxygen Demand & $\mathrm{X}$ & $\mathrm{X}$ \\
\hline Ortho-phosphate & $\mathrm{X}$ & $\mathrm{X}$ \\
\hline Sulphate & $\mathrm{X}$ & $\mathrm{X}$ \\
\hline Organic acids & & $\mathrm{X}$ \\
\hline FOS/TAC & & $\mathrm{X}$ \\
\hline Heavy metals & & \\
\hline
\end{tabular}

particle sizes $\leq 1 \mathrm{~mm}$. These particles partially passed through the filter in the dewatering process and accumulated in the process water. Throughout the experiment, the organic content of the dry matter in the liquid phase was about $70 \pm 3 \%$. As a consequence, the volumetric load increased due to a higher proportion of recirculated process water.

In terms of the recirculation of process water nitrogen and especially ammonia are to be taken into account. Ammonia is easily soluble in water and can accumulate in the recirculated liquid phase. Because of the cow manure the ammonia concentration was about $2 \mathrm{~g} / \mathrm{l}$ at the beginning of the main experiment. Over time the concentration decreased rapidly to $0.75-0.85 \mathrm{~g} / \mathrm{l} /$ unrelated to the process variation. After Christmas break the concentration increased again to $1.05 \mathrm{~g} / \mathrm{l}$ independent of process variation. This leads to the assumption that ammonia will accumulate under conditions like high volumetric loading. Additionally, the activity of microorganisms is affected by switching from quasi-continuous to discontinuous feeding intervals (Hendriksen and Ahring, 1991). The inhibiting effect of ammonia is related to the temperature and $\mathrm{pH}$-value. The adjusted conditions in the main $A D$ experiment should allow concentrations until $3.5 \mathrm{~g} / \mathrm{l}$ (Dauber, 1993). To sum it up, the liquid phase is suitable for recirculation but should be monitored to avoid inhibiting and toxic effects on microorganisms.

Additionally, the organic acids were evaluated. The total sum of organic acids in all reactors and process variations was between 101 to $440 \mathrm{mg} / \mathrm{l}$. Thus, the process stability was not affected as the threshold barrier of $4 \mathrm{~g} / \mathrm{l}$ was not exceeded. The ratio between acetic acid and propionic acid was $>2$. Hence, the degradation and metabolism efficiency is good. Furthermore, the volatile organic acid and buffer capacity ratio (FOS/TAC) was analysed. The ratio was below 0.3 and remained stable. Sufficient buffer capacities for the organic acids are provided by the incoulum cow manure (Schropp, 2016).

\subsubsection{Solid phase}

The solid phase of digestate contained approximately $73 \%$ water. While using smaller particle sizes the water content tended to be $80 \%$, due to a larger surface area and stronger water binding capacities. In the AD approximately $40 \%$ of the organic matter was degraded. The digestate's solid phase has to be composted after the $A D$, since the acquired characteristics do not reach the requried criteria for land use. Depending on the available co-substrate, the parameters will be evaluated furhter in future to attain certificated compost of high quality.

\section{WATER BALANCE}

Selected scenarios represent the substitution of fresh water by recirculation of process water. A treatment of process water did not take place in lab-scale experiments. The required amount of water was calculated using the moisture content of the oFMSW, the retention time and the adjusted dry matter content in the reactor. Five incremental samples collected in one week were unified to one mixed sample. The liquid phase attained in the dewatering process was used partially for recirculation.

Scenario 1 represents the process without process water recirculation. After dewatering $11.3 \%$ of the digestate were separated in form of solid digestate. $88.5 \%$ of the resulting process water, which are respectively $83.7 \%$ of the entire digestate, have to be treated in a waste water treatment plant. The performance and transfering loss amount to $5.6 \%$ (Figure 12).

Scenario 2 represents the case, where approx. 73\% of the process water is being recirculated. After the dewatering process $17.2 \%$ of the digestate were remained in the solid digestate. Therefore, $72.9 \%$ of the resulting process water, which are respectively $60.6 \%$ of the entire digestate, were available for recirculated to the AD process. The performance and transferring loss amounts to $1.8 \%$ (Figure 13). Figure 14 represents the normalisation of the scenario to an input equivilant to 1 ton of bio-waste. Only $26.7 \%$ of the liquid phase have to be discharged to a waste water treatment plant as well as $81.8 \%$ of fresh water being saved because of process water recirculation.

\section{CONCLUSIONS}

The project focused on the conversion of input material in the AD of MBT Freienhufen. Residual waste was substituted by separately collected oFMSW. Reliable and good results were achieved regarding anaerobic degradation by recovering and recirculation process water, while trying out different process variations. The success and quality of anaerobic degradation and biogas production are mainly influenced by the volumetric load. Thus, the course of seasons as well as the quality and ratio of recirculated process 


\section{Water balance BA14}

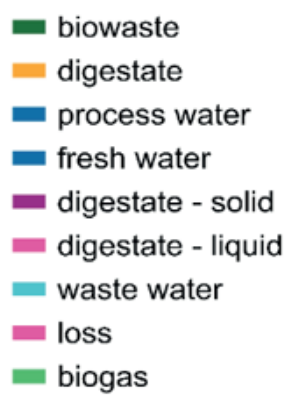

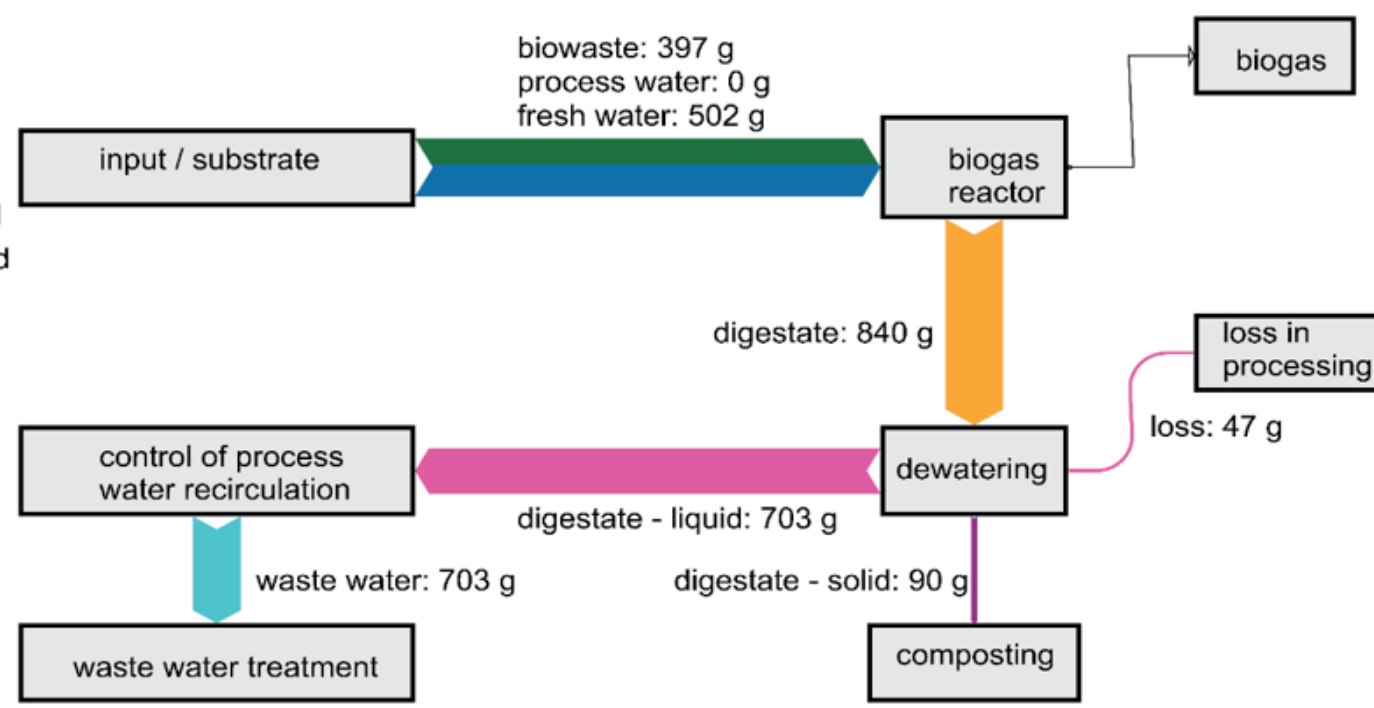

The balance sheet does not complement itself to $100 \%$, causally justified by system-related curves. The difference between input and output in the biogas reactor is assigned to degradation as part of anaerobic process.

FIGURE 12: Simplified water balance.

\section{Water balance BA45}

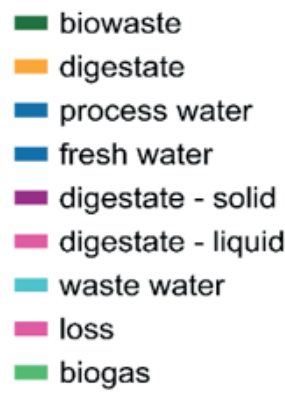

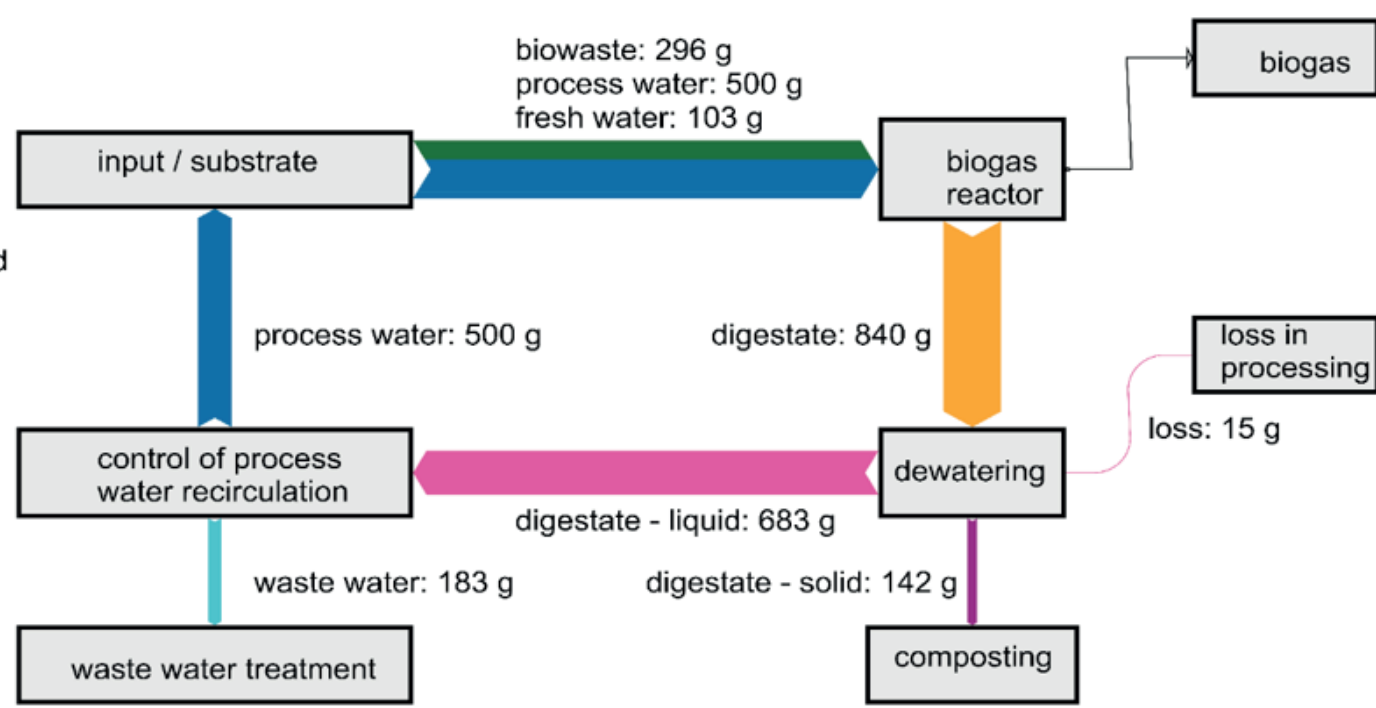

The balance sheet does not complement itself to $100 \%$, causally justified by system-related curves. The difference between input and output in the biogas reactor is assigned to degradation as part of anaerobic process.

water had a major impact on the process.

Since no measurable and reproducible impact of particle sizes was observed, it is recommended to avoid maximum shredding. The higher biogas yield would be out of proportion compared to the additional energy input.

If the digestate's liquid phase would be used as recirculated process water the MBT Freienhufen would be able to substitute large amounts of fresh water. It is recommended to substitute around 65 to $70 \%$ to avoid toxic risks (e.g. ammonification) for microorganisms. If the recirculation of process water was to be implemented to MBT Freienhufen in future, a storage tank with an aeration system would have to be added to the technical concept. The aeration prevents $A D$ processes in the storage tank 


\section{Water balance BA45 - input $1 \mathrm{Mg}$ biowaste}

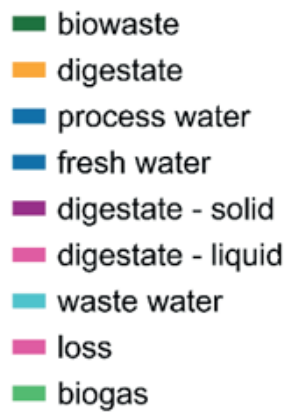

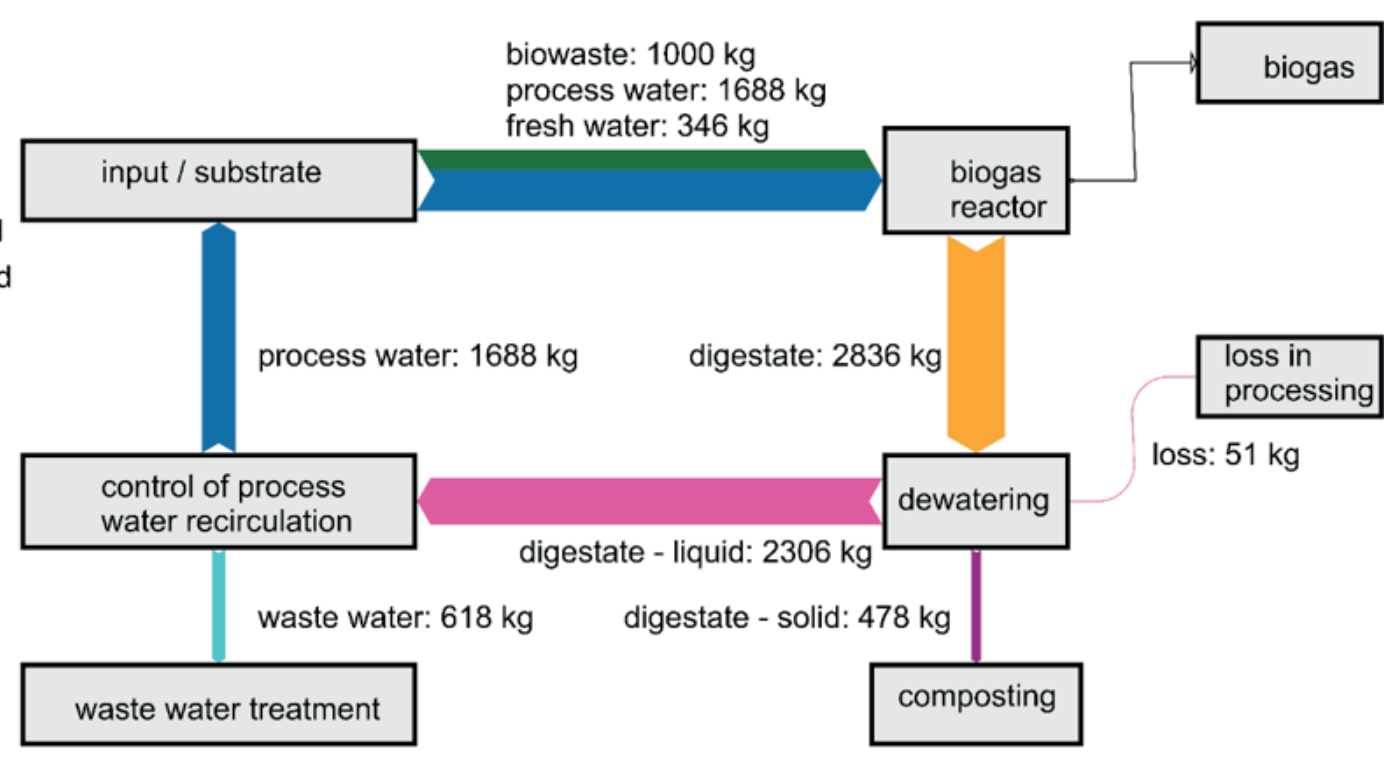

The balance sheet does not complement itself to $100 \%$, causally justified by system-related curves. The difference between input and output in the biogas reactor is assigned to degradation as part of anaerobic process.

as well as settlement of the process water's dry matter content.

In order to use the solid and liquid phases as fertiliser a post-treatment is necessary. The properties of solid and liquid phase did not fulfill legal requirements. Thus, composting with adequate co-substrate or mixing in structure material from the pre-treatment process are options to ensure a good compost composition.

The composition of separately collected oFMSW showed a great variety within the course of the seasons. The MBT Freienhufen has to dispose of the municipal waste, while generating energy. Kitchen waste is suitable for $A D$ processes because of its high water and organic dry matter contents. Green waste in contrary is more suitable for composting. The implementation of the separate collection for oFMSW has to be accepted by the citizens. Hence, the ratio of kitchen waste can increase which leads to a higher performance of AD. In addition, higher ratios of kitchen waste would support the available technical process. The wet fermentation requires large amounts of water which can be covered partially by kitchen waste with a high moisture content.

\section{AKNOWLEDGEMENTS}

This project is kindly funded by Abfallentsorgungsverband Schwarze Elster/ MBT Freienhufen. The author wants to express his/their thanks to the scientific and technical staff for their collaboration and the realization of the project. The author is responsible for the content of this publication.

\section{REFERENCES}

Adwiraah, H., (2015): Bioressourceninventur - Analyse von Stoffströmen zur Bestimmung urbaner Biomassepotenziale in einem Geoinformationssystem (GIS), Ingenieurgruppe RUK GmbH, Stuttgart.

Aschmann, V., Effenberger, M., Gronauer, A., Kaiser, F., Kissel, R., Mitterleitner, H, Neser, S., Schlattmann, M. Speckmaier, A., Ziefreund, G. (2007): Grundlagen und Technik. (Buchverf). Bayerisches Landesamt für Umwelt (LfU). Biogashandbuch Bayern: Materialienband. Augsburg: s.n., p. 4-90.

Dauber, S., (1993): Einflußfaktoren auf die anaeroben biologischen Abbauvorgänge. (book auth.) B. Böhnke, W. Bischofsberger and C.F. Seyfried. Anaerobtechnik: Handbuch der anaeroben Behandlung von Abwasser und Schlamm. Berlin: Springer-Verlag.

Hendriksen, H. V. and Ahring, B. K. (1991): Effects of ammonia on growth and morphology of thermophilic hydrogen-oxidizing methanogenic bacteria. FEMS Microbiology Ecology, Vol. 85, pp. 241246.

Roitsch, J. and Büscher, W., (2009): Charakterisierung und Optimierung von NawaRo-Biogasanlagen in typischen Ackerbauregionen in NRW. Landwirtschaftliche Fakultät der Universität Bonn, Schriftenreihe des Lehr- und Forschungsschwerpunktes USL, Nr. 160.

Schropp, D., (1996): Anaerobe Vergärung von Reststoffen der lebensmittelproduzierenden Industrie, 2016, https://oparu.uni-ulm.de/ xmlui/bitstream/handle/123456789/4304/Dissertation.pdf?sequence=1\&isAllowed=y, website visited 13/09/2018

Schulz, H., Biogas Praxis. Staufen bei Freiburg: ökobuch Verlag, Staufen, p. 20.

Wellinger, A., Baserga, U., Edelmann, W., Egger, K., Seiler, B. (1991): Biogas-Handbuch: Grundlagen-Planung-Betrieb landwirtschaftlicher Anlagen. Aarau: Wirtz, Bde. 2., extensively revised edition.

Zentner, A. (2015): Entwicklung und Implementierung einer Methodik zur Erfassung der Grün-schnittpotenziale von Siedlungs- und Verkehrsflächen in kommunale Verwertungsstrukturen, dissertation, Beiträge zu Abfallwirtschaft/Altlasten, Forum für Abfallwirtschaft und Altlasten e.V. an der TU Dresden Außenstelle Pirna-Copitz (Vertrieb). 